\title{
Functional plasticity and tolerance to drought conditions of 11 apple tree varieties grown in Morocco.
}

\author{
Ouassat S. ${ }^{1 *}$, Allam L. ${ }^{2}$ \\ ${ }^{1}$ Department of Biology, Laboratory of Health and Environment, team of plant protection; Faculty of sciences, Meknes- \\ Morocco \\ ${ }^{2}$ Supervisor, $\mathrm{Tel}+212674904640$
}

\begin{abstract}
In this study, 11 varieties were grown in the experimental chamber in order to determine the morphological, anatomical and physiological characteristics of each. The experimental protocol was carried out under controlled conditions of irrigation, temperature and hygrometry. The values obtained of the thickness, the cuticle, length of the ostiole, density and size of the stomata and then of stomatal and cuticular sweat have made it possible to calculate the stomatic resistance of each variety and to evaluate its potential to adapt to drought conditions. We have highlighted significant differences related to variety through the Duncan test. 4 groups are identified and the results are discussed in this article.
\end{abstract}

Keywords -Malus, Apple varieties, transpiration, stomata, stomatal resistance.

\section{INTRODUCTION}

The apple tree belongs to the Rosacea family, such as pear, peach, and requires for its development the deep, moist soils with a generally neutral $\mathrm{PH}$, the apple tree shows an important requirement for water and cold[1].The apple tree is irrigated. Nearly $99 \%$ of the planted area is irrigated, compared with only $1 \%$ in the countryside. The most used irrigation method is gravity irrigation with $61 \%$ of the area compared with $39 \%$ for the localized irrigation system [2]

Water, a precious element, is notalways available in quantitysufficient for plants, whichgrow in arid and semiarid regions. Among the factors influencing the decisionmaking process in irrigation, the threshold level of available soil water content is critical for irrigation timing [3]According to water requirements, plants are divided

Table. 1 shows the general characteristics of each cultivar Culture conditions:

The protocol was carried out in the experimental greenhouse. The seedlings of these 7 varieties are grown in plastic of $30 \mathrm{~cm}$ diameter and $50 \mathrm{~cm}$ of height, we into three distinct groups: hygrophytes adapted to wet bioclimate and grow in aqueous media and tolerate high humidity levels, from mesophytes to sub humid to semiarid bioclimates and xerophytes to bioclimate arid and high mountains.

Within the xerophytes, we distinguish between two different types, the ephemerophytes, which show nodrought resistance mechanism and whose adaptation is manifested by the development of a short vegetative cycle; on the other hand, physiologically active xerophytes which resist drought by physiological, biochemical, morphological and anatomical mechanisms and structures [4]. They avoid the dehydration of their tissue; by maintaining a high water potential [5], the reduction of transpiration, increased pubescence, development of a strong root system, leaf rolling, sinkingstomata in the epidermis, transformation of the leaves into needles andor scales or spines and the decrease of the conductancestomatic. The varieties examined in this study resist senescence by the acquisition of certain characteristics of adaptations. We then seek to get them out by comparing the morphological and anatomical characteristics of adaptation to drought conditions

\section{MATERIEL AND METHOD:}

In this study, 11 varieties of apple trees grown in the Arbor orchard were subjected to examination to raise their morphological, anatomical and physiological characteristics of seed tolerance, Jeromine ,It ,Red shift, skarlet, Royal-galla ,Obro-galla,Buckey ,Brookfield ,Golden reinders ,Golden Delicious and Anna. For each variety, 5trees are used. 0.0)

opted for the black peat ,because its organic matter content is very high (about 90\%) and its water retention rate is important $(60-70 \%)$, no factor limiting the growth of plants is recorded during our test.

Varietal density of stomata: 
In the apple tree (rosacea family), the stomata are located on the underside of the leaves. The density of stomata was determined from five measurements. Five fully developed leaves were selected from five plants of the same variety. Five Repetition for each variety to produce a representative mean value. Practically, the density of stomata (number of stomata per square millimeter) is obtained from the foliar epidermal implications of a colorless adhesive tape; the prints obtained are then glued to a slide. Stomata are counted microscopically on slides graduated in millimeters.

\section{Length of the stomata ostiole:}

The measurements were carried out under a microscope(Nikon E200 LED) with a graduated eyepiece micrometer $(\mu \mathrm{m})$. Thin sections leaves were prepared and their contents was destroyed by the hypochlorite of sodium. The cuts were doubled coloration with alumina carmine and green of iodine to differentiate the different cell compartments. For each variety, five plants been used and, for each plant, the length of stomatal diffusion or length of the ostiole was measured in average over five cuts.

\section{Varietal resistance of stomata:}

The stomatal resistance of the pores as described by[6]is computed by the following general equation:

$\mathrm{R}_{\mathrm{s}}=[(\mathrm{L} / \mathrm{ncb})+(\log (4 \mathrm{c} / \mathrm{b})) / \mathrm{nc}]^{*}\left(1 / \mathrm{D}_{\mathrm{v}} \mathrm{n}\right)$

It is first necessary to determine the fundamental parameters of this equation such as:

Rs: Stomatal resistance (s / m)

c: half-length of the stomatal pore (m)

$\mathrm{b}$ : half width of the stomatal pore $(\mathrm{m})$

$\mathrm{L}$ : length of the ostiole or diffusion of the pore $(\mathrm{m})$

$\mathrm{n}$ : density of stomata (number of stomata per $\mathrm{m} 2$ )

Dv: diffusion of water vapor into air $(\mathrm{m} 2 / \mathrm{s})$

At each luminous intensity applied to the plants, epidermal fragments of 5 leaves of each variety are taken

Table.1. In general, the cuticular thickness varies according to the varieties and age of the leaves, the to determine the dimensions of the stomatal pore at the opening.

Thickness of the cuticle and Vessel-cuticle length:

For this purpose, we have applied the same preceding preparations for the determination of the length of the ostiole or stomatal diffusion in order to determine the thickness of the cuticle and the length separating the vessels of the cuticle from the seven varieties. Five plants are retained for each variety and 10 leaves for each plant, 10 sections are observed under the microscope (NikonE200 LED).

\section{Cuticular sweat:}

The experimental protocol related to the determination of cuticular sweat consists in placing the plants in a chamber for an hour in a dark tight chamber to prevent any stomatal sweat. To avoid the evaporation of water from the substrate-culture system, pots are wrapped perfectly in plastic. We then proceed to measure the difference in weight related to the time interval used and to the leaf area of the plant, hence the loss of water dissipated cuticularly.

The sweat is due essentially to the opening of the stomata during the phase of light. We have projected light fuses at varying light intensities. The light source $(100 \mathrm{~W}$ thermal projector) can be fixed at different positions. For each position (height), five plants of the same vegetable variety, receive an intensity of luminous intensity for an hour. Thus, by the difference in weight projected at the leaf surface, one can determine the stomatal sweat of each cultivar and for each luminous intensity.It should be noted that the luminous intensity was measured using a photopile (LI 1600) and expressed in micromoles of photons per square meter per second $(\mu$ moles $/ \mathrm{m} 2 / \mathrm{s})$.

\section{RESULTS}

Thickness of the cuticle and cuticular sweat

The average values of the cuticular thicknesses are given in 0.0 )

lowest values are observed in the Golden $(0.33 \pm 0.02)$, while the most are recorded in Jeromine $(0.58 \pm 0.0)$

Table.1: Mean height of the scions, mean thickness of the cuticle ( $\mu \mathrm{m})$.

Mean values with the same letter do not differ significantly according to the Duncan test at the 1\% threshold. The pear did not show a variation in sound cuticular thickness

\begin{tabular}{ccccccccc}
\hline variety & $\begin{array}{c}\text { Average height of plants } \\
(\mathbf{c m})\end{array}$ & tree1 & tree2 & tree3 & tree4 & tree5 & average & st dev \\
& 95,4 & 0,58 & 0,59 & 0,56 & 0,58 & 0,58 & $0,58 \mathrm{a}$ & 0,01 \\
\hline Jeromine & 96,3 & 0,55 & 0,55 & 0,54 & 0,58 & 0,53 & $0,55 \mathrm{a}$ & 0,02 \\
Red shift & 92,7 & 0,58 & 0,56 & 0,56 & 0,54 & 0,59 & $0,57 \mathrm{a}$ & 0,02 \\
skarlet & 95 & 0,55 & 0,54 & 0,54 & 0,54 & 0,56 & $0,54 \mathrm{a}$ & 0,01 \\
\hline It & & & & & & &
\end{tabular}




\begin{tabular}{|ccccccccc|}
\hline \hline Golden Deliciuos & 96,8 & 0,32 & 0,35 & 0,31 & 0,36 & 0,33 & $0,33 \mathrm{c}$ & 0,02 \\
\hline Golden reinders & 99,5 & 0,35 & 0,36 & 0,35 & 0,36 & 0,36 & $0,35 \mathrm{c}$ & 0,00 \\
\hline royal Gala & 98,4 & 0,46 & 0,47 & 0,46 & 0,46 & 0,47 & $0,46 \mathrm{~b}$ & 0,01 \\
\hline Obro-galla & 98,3 & 0,45 & 0,46 & 0,45 & 0,45 & 0,45 & $0,45 \mathrm{~b}$ & 0,00 \\
\hline Brookfield & 99,4 & 0,43 & 0,42 & 0,43 & 0,44 & 0,44 & $0,43 \mathrm{~b}$ & 0,01 \\
\hline Buckey & 97 & 0,46 & 0,46 & 0,46 & 0,47 & 0,47 & $0,46 \mathrm{~b}$ & 0,01 \\
\hline Anna & 101,2 & 0,50 & 0,51 & 0,51 & 0,50 & 0,52 & $0,51 \mathrm{a}$ & 0,01 \\
\hline
\end{tabular}

The measurements taken at the end of each hour of weight of the 10 plants of each variety gave the mean values of cuticular losses of water.Fig. 1 represents the results.

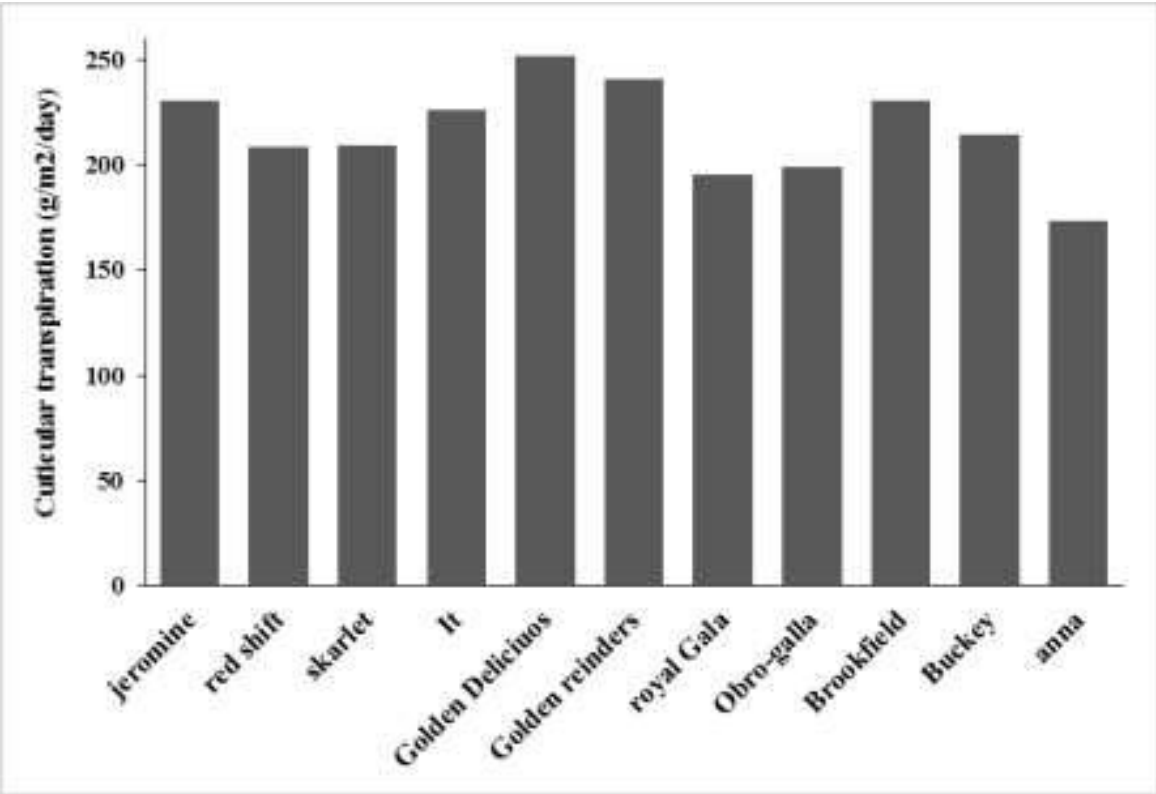

Fig.1: The cuticular transpiration of the 11 varieties studied ( $\mathrm{g} / \mathrm{m} 2 /$ day).

\section{Vessel-cuticle length}

The length from the vessels to the cuticle represents the path traveled by the water to pass to the outside air through the path of stomatal sweat or through the path of cuticular sweat. When the distance traveled by the water Table.2. The difference between these two limit values is $1.7 \mu \mathrm{m}$

Table.2: Mean lenght from vessels to cuticle ( $\mu \mathrm{m})$, mean stomatal density (number of stomata per $\mathrm{mm}^{2}$ ), mean lenght of the stomata ostiole $(\mu \mathrm{m})$.

The means followed by the same letter do not differ significantly according to the Duncan test at the 1\% threshold.

\begin{tabular}{|c|c|c|c|}
\hline variety & $\begin{array}{c}\text { Vessel-cuticle } \\
\text { length }(\mu \mathrm{m})\end{array}$ & number of stomata/mm² & Length of the stomata ostiole $(\mu \mathrm{m})$ \\
\hline Jeromine & $8,05 \mathrm{c} \pm 0,29$ & $345,7 b \pm 3,4$ & $1,58 b \pm 0,17$ \\
\hline Red shift & $8,4 \mathrm{~b} \pm 0,21$ & $335 b \pm 3,1$ & $1,56 b \pm 0,17$ \\
\hline Skarlet & $8,02 c \pm 0,18$ & $334,6 b \pm 1,6$ & $1,49 b \pm 0,20$ \\
\hline It & $8,08 \mathrm{c} \pm 0,32$ & $343 b \pm 4,1$ & $1,48 b \pm 0,22$ \\
\hline Golden Deliciuos & $7,35 \mathrm{~d} \pm 0,22$ & $361,7 \mathrm{a} \pm 3,7$ & $0,95 \mathrm{c} \pm 0,11$ \\
\hline Golden reinders & $7,33 \mathrm{~d} \pm 0,17$ & $360 \mathrm{a} \pm 2,6$ & $0,97 \mathrm{c} \pm 0,16$ \\
\hline royal Gala & $8,97 \mathrm{a} \pm 0,16$ & $329,4 c \pm 2,8$ & $1,08 \mathrm{c} \pm 0,23$ \\
\hline Obro-galla & $8,89 a \pm 0,14$ & $330 \mathrm{bc} \pm 1,8$ & $1,09 \mathrm{c} \pm 0,15$ \\
\hline Brookfield & $7,42 \mathrm{~d} \pm 0,32$ & $344,2 b \pm 2,1$ & $1,47 b \pm 0,35$ \\
\hline Buckey & $8,33 b \pm 0,29$ & $334,7 \mathrm{~b} \pm 2,1$ & $1,53 \mathrm{~b} \pm 0,14$ \\
\hline
\end{tabular}

between the vessels and the cuticle is great, the resistance to the outflow is great. The lowest length is $7.33 \pm 0.17$ $\mu \mathrm{m}$ (in Golden reinders) and the highest is in the Anna

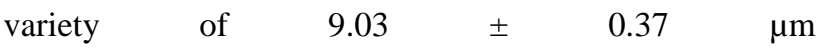




$\begin{array}{llll}\text { Anna } & 9,03 \mathrm{a} \pm 0,37 & 312,9 \mathrm{~d} \pm 4,9 & 2,11 \mathrm{a} \pm 0,22\end{array}$

\section{Stomatal resistance and stomatal sweat}

The average stomatal density is 339.3 in the apple tree, the minimum density is observed in the Anna variety (312.9d \pm 4.9)and the high-priced Golden Delicious variety $(361.7 \mathrm{a} \pm 3.7)$.
During stomatal sweat, water vapor passes from the substomatic chambers to the outside air, the length of the ostiole (the length of stomatal diffusion). This depends on the variety. It is $0.95 \pm 0.11$ and $0.97 \pm 0.16 \mu \mathrm{m}$ respectively for Golden delicious and Golden reinders whereas for Anna it is larger $(2.11 \pm 0.22 \mu \mathrm{m})$

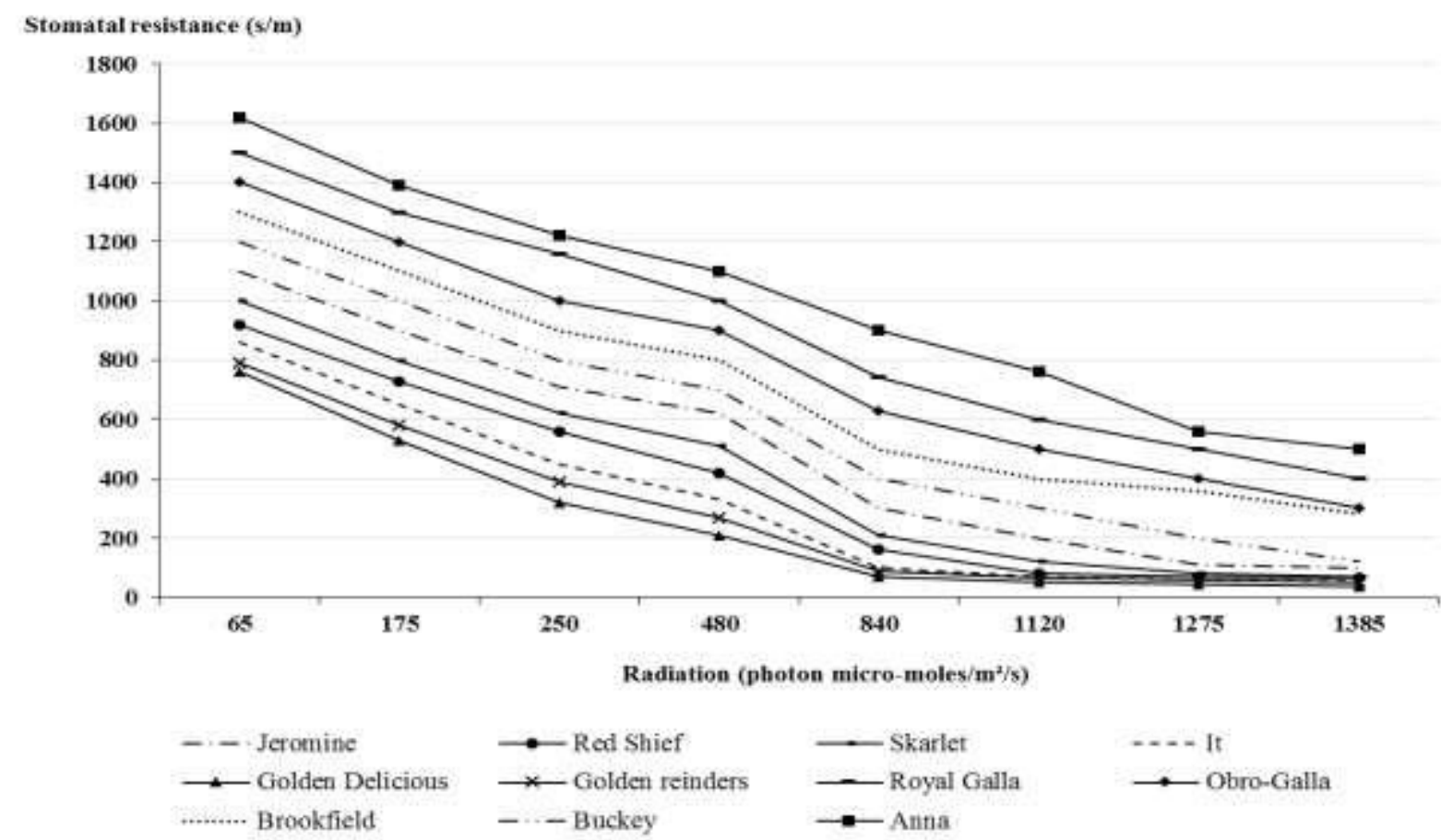

Fig.2: variation of stomatal resistance $(\mathrm{s} / \mathrm{m})$ with shortwave radiation.

The measurements of the stomatal sweat in the 11 varieties are shown in

Fig.3. The first reading reports the higher values of the golden varieties than the intensity of the light.

\section{Stomatal transpiration}

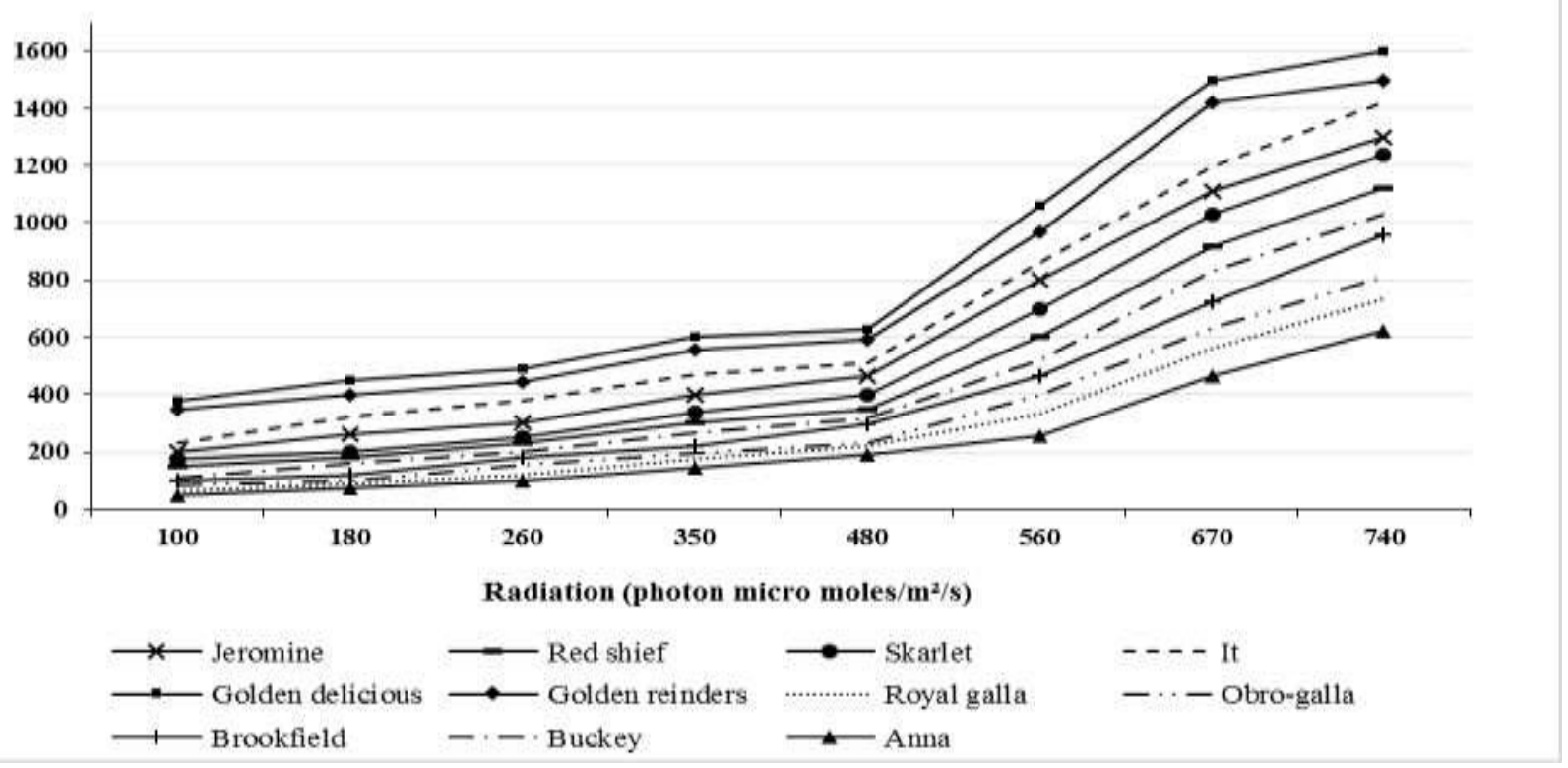

Fig.3: variation of stomatal transpiration $(\mathrm{g} / \mathrm{m} 2 / \mathrm{h})$ with shortwave radiation 
The analysis of the main components of the morphological and anatomical parameters in the cited varieties makes it possible to describe their physiological behavior in order to adapt to drought conditions, the results are shown in Fig.4

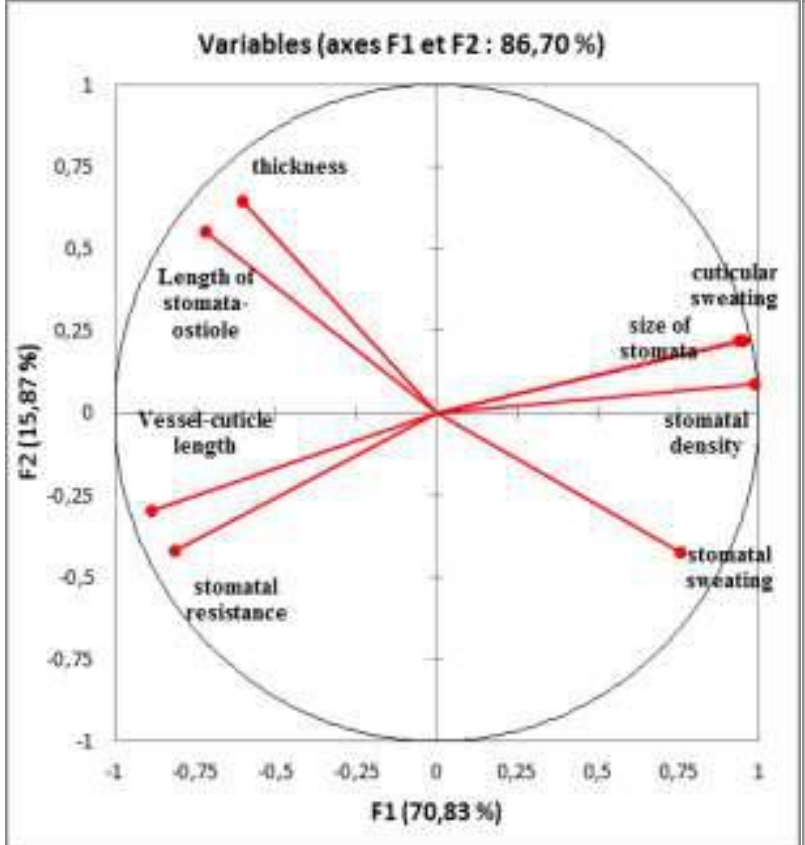

(a)

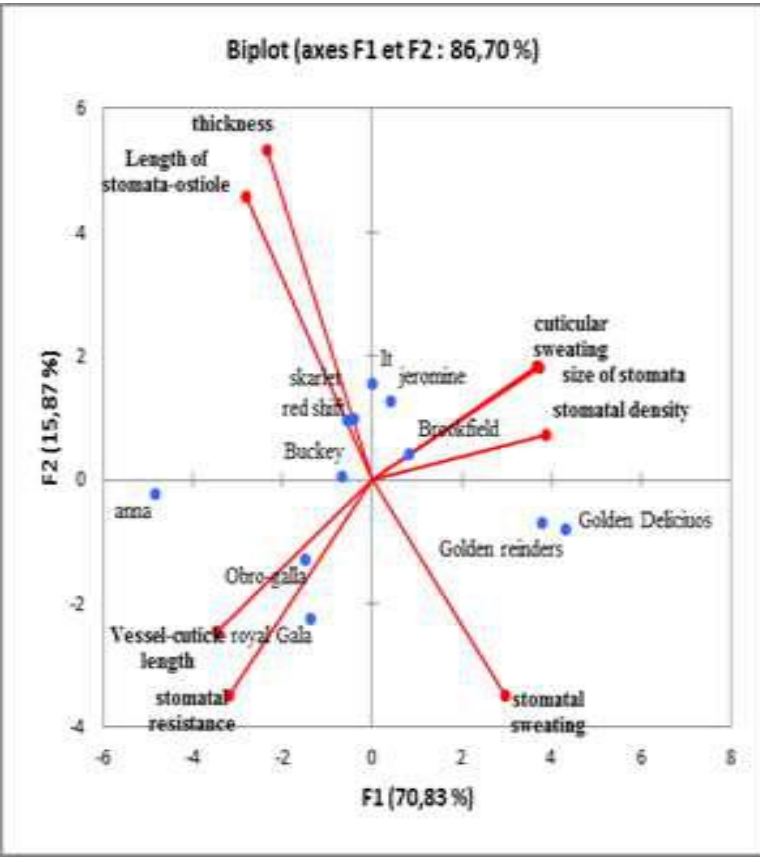

(b)

Fig.4: Principal Component Analysis (PCA). (a): circle of correlations. (b): projection of the varieties in the plane (Axis F1 and $F 286.70 \%$ ).

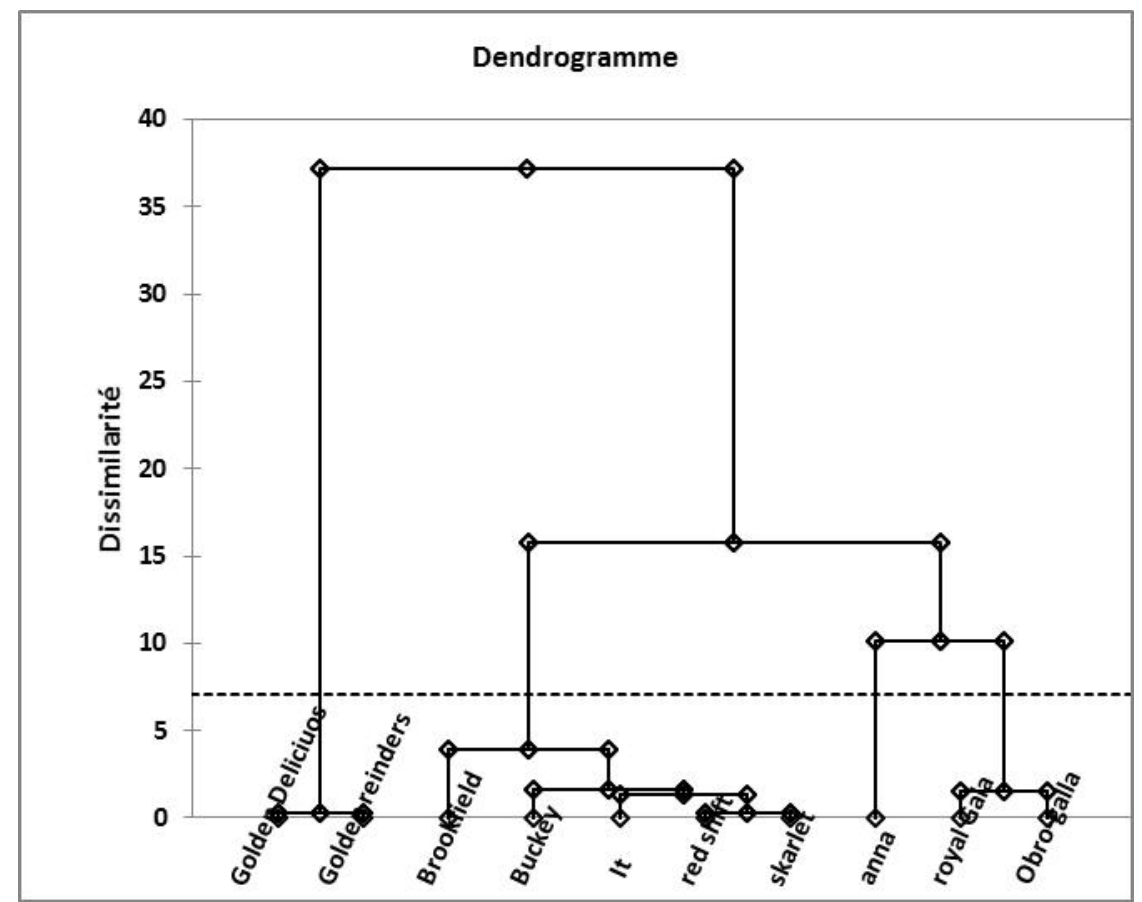

Fig.5: Dendrogram of the grouping of the varieties studied according to the method of Ascending Hierarchical Classification $(A H C)$

\section{DISCUSSION}

The vascular plant is always placed in a compromise between photosynthesis and sweat. In developing the dry matter, the plant loses in aconcomitant water through perspiration.In water-deficient areas ofrainfall, to adjust the level of production agriculture to water requirements, it is imperative to practice irrigation. However, water resources are limited and the demands are constantly increasing parallel to the areas growing crops. So, one aspect of the research is attached to the determination of performing varieties adapted or tolerant to drought, able to improve efficiency of water use in irrigated cropsor 
dry. Physiologically, the decrease of water in the soil is manifested bystomatal regulation in the leaves[7]. This phenomenon is often married to a fall in stomatal conductance [8]which is of course at the expense of other physiological processes such as photosynthesis [9]. Faced with this problem of drought, plants that tolerate water deficit, resistsenescence and adjust their need for production to the environmental conditions. Putting this form of adaptation, it is not necessary to bring all the water irrigation required by crops.

According to the results, the Golden varieties appear to be water demanding, their anatomical characteristics such as cuticle thickness, vessel-cuticle length, stomatal density and the diffusion length favoring high perspiration. On the other hand, the red varieties of Jeromine, Red shield and It varieties have anatomical characteristics that reduce transpiratory water losses relatively more than Anna, which is a variety adapted to dry climatic conditions.

The Galla, Obro-galla, Brookfield, and Buchey varieties show no significant differences in anatomy and morphology as well, cuticle thickness, vessel-cuticle distance, theirstomatic densities, and diffusion length decrease stomatal transpiration (Table.1). The thickness of the cuticle has no effect on cuticular transpiration, whereas the diffusion path between the vessels and the cuticle acts on stomatal sweat[10].The it is true for the Jeromine, Red shield and Skarlet varieties and the clon of the golden, the Anna variety is significantly different from the other varieties. Sweat depends mainly on stomatal conductance, density and size of stomata. This dependence is verified for the varieties studied and our result is similar to that obtained by [11] under three water regimes.The varieties Galla and Obro-galla show similar stomatal resistance due mainly to the long length of their ostiole. Similarly, for the Golden varieties, which resemble each other anatomically, and physiologically by a high density of stomata and in one particular case the Anna constitutes a variety apart but the journey traversed by water approaching the varieties Galla and Obro-galla in the areas of transition to the mountain

Fig.2.The regulation of cuticular permeability depends essentially on the composition and spatial conformation and structural structuring of the cuticle as well as on its thickness[12]Among the 11 apple varieties studied, the varieties Golden delicious, golden reinders, Red chief, Skarlet and Jeromine are classified as demanding varieties of water. Under conditions where irrigation water is limited, it is necessary to cultivate the Anna and Royal Galla varieties or, if necessary, the Obro-galla or Buckey varieties. The size of the stomata is estimated by measuring the length $\mathrm{L}$ of the guard cells. For each clone. The number of stomata per leaf can be expressed either by the stomatal density (number of stomata per $\mathrm{mm}^{2}$ or by $\mathrm{cm}^{2}$ ) or by the stomatal index (percentage of stomata relative to the total number of epidermal cells). This index is not usablein the apple tree because cells with very irregular contours are difficult to identify; we retained the stomatal density expressed in the number of stomata per $\mathrm{mm}^{2}[13]$.The multiple comparison of the mean stomatal size showed a significant difference between the golden and Anna varieties on the one hand and the galla varieties on the other hand, whereas it is not significant between Jeromine and red shield as well as skarlet which seem to occupy the same geographies

With respect to stomatal density, the "multiple" comparison of the means shows a significant difference at the threshold $\alpha=0.001$ between the 4 clones. The stomatal densities of the Golden varieties are the highest and the lowest value is recorded in the Anna. The Duncan comparison test revealed a significant difference between the stomatal densities of the golden and red varieties as well as with the royal Galla Obro-galla, Brookfield and Buckey. On the other hand, the difference between the Jeromine, skarlet and red chief varieties and between the Galla, Brookfield and Buckey varieties is not significant. The anatomical parameters studied in apple varieties are regulators of adaptation to environmental and production conditions. In mountain areas, the Golden delicious, golden reinders, Jeromine, red shield and skarlet varieties form more spurs and twigs, indicative of a good adaptation to the environment. Its flowering is relatively clustered and production is better. During the maturity of the fruits, the rapid disappearance of chlorophyll gives way to a more intense coloration. Moderate temperatures and high thermal amplitudes favor the synthesis of the pigments responsible for good coloring, especially red[14]. The fruit is firm, crunchy and more fragrant when fully mature. Under these conditions, the usual range of Golden Delicious and Golden reinders is to be extended with the Red Chief, Jeromine and other nonstudied cultivars. There is a strong demand for red fruits, indicating that future plantings should be based on colored varieties.

The varieties show an increasing stomatal resistance by applying increasingly higher light radiations. In fact, plants open their stomata to light in order to ensure their gaseous exchange and to perspire, but mechanisms of resistance to dehydration are developed and expressed in stomatal resistance, which is also explained by the set of anatomical, morphological and physiological parameters mentioned above. In Fig.3, the Anna variety appears to be more resistant to dry conditions, the others less, whereas the Golden varieties are less resistant and this is due to their particularities discussed.

The projection of the values confirms this result Fig.4, the thickness of the cuticle is negatively correlated with 
cuticular (-0.45) and stomatal sweat (-0.6). The transpiration through the stomata ; depends mainly to the density , and the length of the ostiole that when it increases, the stomatic losses of the water become minimal, joining to it the geometry of the leaves[6] The Jeromine, It, Skarlet and Red chief varieties, constitute a clon;whose ,morphological, anatomical and physiological characteristics are homogeneous Fig.4. To which group Brookfield varieties can be affiliated by the similar size of the stomata and by values close to cuticular sweat and Buckey variety on the basis of stomata length ostiole.

The average thickness, cuticular thickness, stomatal density and average ostiole length give the Royal Galla, Obro-galla, Brookfield and Buckey varieties a physical adaptation to the conditions of the transitional media towards altitude, these semi-early varieties are perfectly adapted and their maturity comes to fill a vacuum in the production schedule. They give respectively light yellow and light carmine red fruits. Their texture is crisp and the flow on the market is easy

The Golden delicious and golden reinders varieties have high stomatal densities and short water vapor diffusion lengths, their stomatal resistancebeing lower than those of the other varieties

Fig. 2 showsat low light, the Anna varietyhas the most stomatalhigh while the highlights, the Brookfield varietyshows a stomatal resistance similar to that of Obrogalla. The Golden varieties show the valuesthe lowest for all intensitiesillumination. For the 11 varieties studied, thestomatic resistance is dependent onthe light. The Anna variety has a stomatal regulation that makes it possible to reduce the lossestranspiratory moisture while these regulations are very low in golden delicious and reinders varieties.The application of the Hierarchical Ascending Classification (HAC) method makes it possible to group all the varieties in question, the result confirms the morphological, anatomical and physiological convergences and divergences that contribute to the classification of the varieties. Class 1 of Red shield, Skarlet, It, Brookfield and Buckey. Class 2 of Golden delicious and golden reinders. Class 3 of Royal Galla and Obro-Galla and a class with unique variety of Anna (Fig.5).Note that this classification brings together the Brookfield and Buckey varieties of Skarlet and Red chief, even though the anatomical and physiological characteristics measured resemble those of the Galla varieties.

\section{CONCLUSION}

Thanks to their anatomical and physiological characteristics, the Anna varieties and the Galla, ObroGalla and Buckey varieties can tolerate the conditions of lack of water; these conditions characterize the plains and the zones of transition towards the mountain in Morocco and in the southern outline of the mediteranea.The long path of diffusion, the large thickness of the cuticle and the lower stomata size and density give them a resistance to dryness. On the contrary, the varieties of red apple trees and varieties Golden are much more demanding in terms of water and cold, their anatomical and physiological characteristics classify them in the range of altitude variability, in some cases they may be present in the transition zones but the quality and volume of production not meet the wishes of producers.

\section{ACKNOWLEDGEMENTS}

We would like to thank the head of the plant physiology team for their help during the experiments and the availability of the experimental greenhouse; we also thank all the students for their availability and their coup of hand.

\section{REFERENCES}

[1] Raven P.H. and al., Plant's biology, New York: De Boeck, 2014.

[2] MAPM, "Note de veille "pomme"," Direction de la stratégie et des statistiques, Rabat, 2014.

[3] Ali S., "Planting Patterns and Deficit Irrigation Strategies to Improve Wheat Production and Water Use Efficiency under Simulated Rainfall Conditions," Frontiers in plant science, vol. 54, pp. 1-17, 22 August 2017.

[4] Levitt J., Responses of plants to Environmental stress. chilling,Freezing and High Temperature stresses, vol. 1, A. Press, Ed., New York: 2nd Edition, 1980.

[5] Boyer J. S., "Subcellular mechanisms of plant response to low water potential," Agricultural Water Management, vol. 7, no. 1-3, pp. 239-248, September 1983.

[6] W. P. E. Parlange J. Y., "Stomatal Dimensions and Resistance to Diffusion.," Plant Physiology., vol. 46, no. 2, pp. 337-342, August 1970.

[7] Calvet C. J., "Investigating soil and atmospheric plant water stress using physiological and micrometeorological data," Agricultural and Forest Meteorology, vol. 103, no. 3, pp. 229-247, 2000.

[8] Girona J. and al, "Evapotranspiration and soil water dynamics of peach trees under water deficits," Agricultural Water Management, vol. 54, no. 2, pp. 107-122, 25 March 2002.

[9] Shangguan Z. P. and al, "Nitrogen nutrition and water stress effects on leaf photosynthetic gas exchange and water use efficiency in winter wheat," Environmental and Experimental Botany, vol. 44, no. 2, pp. 141-149, October 2000. 
[10]Denden M. et al., "Action du trajet foliaire de diffusion de l'eau et de l'épaisseur de la cuticule sur la transpiration," Science et changements planétaires / Sécheresse, vol. 16, no. 2, pp. 125-129, 2 Juin 2005.

[11] Charreyron M., "Suivi de la transpiration et de la conductance stomatique chez le pommier sous trois régimes hydriques : irrigation, sécheresse et réhydratation," Clermont Ferrand, 2011.

[12] Tranquillini W., Water relations and alpine timberline.In : Lange $O$, Knappen L, Schulze ED,eds. Water and plant life, Berlin ; Heidelberg ;New York: Springer Verlag,, 1976.

[13] Slack E. M., "Studies of stomatal distribution on the leaves of four apple varieties," Journal of Horticultural Science, vol. 49, no. 1, pp. 95-103, 1974.

[14] Oukabli A., "Le pommier, une culture de terroir en zone d'altitude,Transfert de technologie en Agriculture.," Bulletin mensuel d'information et de liaison du PNTTA, no. 115, pp. 1-5, Avril 2004. 